young as well as the old. They do not welcome new additions to their ever-expanding list of lifestyle limitations, or being labelled as excessive drinkers by their general practitioner if they choose to drink a pint of beer at night. A holistic approach might well conclude that in many instances an elderly person will be happier and even healthier (in the holistic sense) with a pint, or perhaps even two, than without them.

1 Royal College of Psychiatrists. Psychiatrists call for action to tackle substance misuse in older people (press release). Royal College of Psychiatrists 2011 (http://www.rcpsych.ac.uk/press/pressreleases2011/ ourinvisibleaddicts.aspx).

2 Older Persons' Substance Misuse Working Group. Our Invisible Addicts (College Report CR165). Royal College of Psychiatrists, 2011 (http:// www.rcpsych.ac.uk/files/pdfversion/CR165.pdf).

3 Hughes D. People over 65 should drink less, a report says. BBC News Health 2011; 22 June (http://www.bbc.co.uk/news/health-13863196).

Rafael Euba, consultant psychiatrist and senior lecturer in old age psychiatry, Oxleas NHS Foundation Trust, Memorial Hospital, London, UK, email: Rafael.Euba@oxleas.nhs.uk

doi: $10.1192 /$ pb.35.9.354a

\section{The health status of prisoners is the real challenge}

Exworthy et al are to be commended for their attempt to go beyond the existing interpretation of the doctrine of equivalence of health service delivery in prison healthcare. This has driven improvements in prison healthcare for the past 10 years. However, they fail to identify the next challenge, that of achieving equal health status for prisoners and non-prisoners; this should be the doctrine that informs the strategy for service delivery for the next 10 years. Given the exceptionally high rates of mental and physical ill health in the prison population, not entirely explicable in terms of their sociodemographic profile, this will demand significantly greater investment than is currently the case. Per capita prison healthcare cost $£ 2769$ in 2007-2008, of which only $£ 316$ was for mental healthcare. ${ }^{2}$ However, the advent of outcome-based payments for healthcare and for the management of offenders ${ }^{3}$ allows for the relationship between health gain and criminological outcomes to be explored more rigorously.

The authors cite the UN International Covenant on Economic, Social and Cultural Rights as a guide to future prison health monitoring. This contains nothing to which anyone may object, but it is not specific to this very challenging area of healthcare. Exworthy et al largely neglect the advances in thinking by both the Department of Health ${ }^{4}$ and Her Majesty's Inspectorate of Prisons, ${ }^{5}$ which have led to much improved, relevant markers of activity, performance and outcome in routine review of contract delivery by prison health providers, as well as the role of the Care Quality Commission in assessing prison healthcare. In truth, they look out of step with commissioners and providers of healthcare who are already engaged in the detailed determination of local standards based on a grasp of local needs, for example those of young offenders, older prisoners and women.

Exworthy et al have, as might seem reasonable, a focus on mental health and the important issue of prison transfers. Such problems are relatively rare, although they need quicker resolution than is currently the case. However, they say nothing about primary care, including primary mental healthcare, which is poorly modelled. Nor do they comment on the treatment of drug and alcohol problems, difficulties that compound the management of serious mental illness but where there have been huge improvements in the past 10 years. Most of the prison health budget is devoted to these two areas. Prisoners have often had poor access to primary care and are highly likely to have drug and alcohol problems. The de facto 'polyclinic' nature of the prison environment is different from the external community, but this may be an advantage rather than a disadvantage for rapid healthcare delivery. Within a short period of time a prisoner can have a health check and be stable enough to reflect and plan for the future. For this to work, practitioners, including senior psychiatrists, will be required to operate in an integrated and multifaceted system of holistic care delivery where acute mental illness, for all its headline grabbing potential, is not the main issue.

\section{Declaration of interest}

A.B. and F.A. are joint clinical directors in offender care, Central and North West London NHS Foundation Trust, and work clinically and have clinical director responsibility for a range of health services delivered to three London prisons.

1 Exworthy T, Wilson S, Forrester A. Beyond equivalence: prisoners' right to health. Psychiatrist 2011; 35: 201-2.

2 Brooker C, Duggan S, Fox C, Mills A, Parsonage M. Short-Changed: Spending on Prison Mental Healthcare. Sainsbury Centre for Mental Health, 2008.

3 Ministry of Justice. Breaking the Cycle: Effective Punishment, Rehabilitation and Sentencing of Offenders. TSO (The Stationery Office), 2010.

4 Department of Health, National Offender Management Service, Her Majesty's Prison Service. Guidance Notes: Prison Health Performance and Quality Indicators. Department of Health, 2008.

5 Her Majesty's Inspectorate of Prisons. Expectations: Criteria for Assessing the Conditions in Prison and the Treatment of Prisoners. HMIP, 2008.

Annie Bartlett is reader in forensic psychiatry, St George's, University of London, email: abartlet@sgul.ac.uk; Farrukh Alam is a consultant psychiatrist, Central and North West London NHS Foundation Trust.

doi: $10.1192 / p b .35 .9 .355$

\section{Personality disordered offenders - complex patients requiring more expertise}

The ongoing debate on the management of personality disordered offenders has been further stimulated by the recently concluded Department of Health and National Offender Management Service joint consultation paper on the proposed personality disorder care pathway. ${ }^{1}$

The Labour government's flagship Dangerous and Severe Personality Disorder pilot programme is being scaled down at present to make way for national personality disorder services. ${ }^{2}$ Approaching the conclusion of the Programme, clinicians are still looking at the most effective treatment regimes and politicians are still striving to ensure that the public protection element of treatment is not overlooked. Both parties are labouring to find the most effective way of managing this group of offenders who are considered to be 'difficult to treat', 'high risk' and 'carrying a high morbidity and stigma'.

Thus, we welcome and value the suggestion of early identification and provisions for a suitable care pathway for personality disordered offenders. ${ }^{1}$ A standardised early identification system with clear pathways of treatment is likely 